DOI: 10.1515/hssr -2016-00016

\title{
Post-mortem Photography: the Edge Where Life Meets Death?
}

Melania Borgo*

University of Insubria, Italy

Marta Licata $^{* *}$

University of Insubria, Italy

Silvia Iorio ${ }^{* * *}$

University Sapienza, Rome, Italy

\begin{abstract}
Why would we ever take a picture of a dead person? This practice began as a way to perpetuate the image of the deceased, rendering their memory eternal Victorians thought that it could be useful to have portraits of their dead loved ones. Certainly, subjects in post-mortem photos will be remembered forever. However, we must ask two more questions. Are they people portrayed as if they were still alive? Or on the other hand, are they bodies that represent death? Our paper takes an in-depth look at different iconographical styles as well as photographic techniques and religious and ethical reasons behind memento mori photos during the Victorian Age.
\end{abstract}

Keywords

Post Mortem Photos, Memento Mori, Victorian Age

Department of Biotechnology and Life Sciences, University of Insubria (Varese), O. Rossi , 9, 21100 Varese, Italy; melania.borgo@uninsubria.it

** Department of Biotechnology and Life Sciences, University of Insubria (Varese), O. Rossi , 9, 21100 Varese, Italy; marta.licata@uninsubria.it

${ }^{* * *}$ Department of Molecular Medicine, Unit of History of Medicine, Sapienza University of Rome, Viale dell'Università 34a, 00185, Rome, Italy; silvia.iorio@uniroma1.it 
Melania Borgo, Marta Licata, Silvia Iorio, Post-mortem Photography: the Edge ...

HSS, vol. V, no. 2 (2016): 103-115

\section{Introduction}

Post-mortem photographs were first seen in England during Victorian times. They later spread to the rest of Europe and to the United States. In a short period of time, this tradition attracted a growing population, however scholars paid little attention to this practice until the 1950s. Authors such as Rinhart (Rinhart, 1967) and Welling (Welling, 1978) believed that the post mortem phenomenon was an American invention, while M. Lesy (Lesy, 1973) tried to understand the anthropological meanings of this practice (Orlando, 2010).

Today, the practice of taking pictures of the dead has negative connotations, while during the Victorian age it represented a true homage to their memory. Paradoxically, these post-mortem photos offered a chance to get the last "picture of life" of "the dead", before time corrupted the body. The main reason, as given by Victorians, to take photographs during the delicate moment of the death was the need to perpetuate the image of the deceased, making them eternal (Licata, 2013). The photographic representation of the body, rather than its preservation (embalming, mummification), turns into a way to challenge immortality. Before driving into the core of the cultural and anthropological aspect of this phenomenon, we first need to clarify that the birth of the post mortem portrait was not the result of the invention of photography. On the contrary, this phenomenon was essential for its development. The success of the post-mortem theme in fact dates back to the Renaissance, when the clergy and nobility were portrayed on their deathbeds. In the nineteenth century, the creation of daguerreotype was a milestone for memento mori. The lower costs of photography allowed post mortem portraits to reach the lower classes. This was a new form of portrait. Starting in 1840, post-mortem pictures became so popular that they were the most lucrative source of income for photographers. We find evidence of this in an advertisement that appeared in the Humphrey Journal: "Gallery daguerreotypes for sale - the only one in the city of 20,000 inhabitants and where the photographs of deceased persons pay for itself all the costs" (Humphrey Journal, 1854: 33). Therefore, these photographs replaced previous pictures and portraits of death, becoming at this stage a "false" portrait of life. In fact, for the majority of people, these kinds of pictures were the only portrait of the deceased person. Often there was no possibility to get a photograph while the person was alive. 
Melania Borgo, Marta Licata, Silvia Iorio, Post-mortem Photography: the Edge ...

HSS, vol. V, no. 2 (2016): 103-115

In this paper, we would like to present the anthropological phenomenon of post mortem photos in the second half of $19^{\text {th }}$ century, focusing on the reasons behind the onset of this particular custom.

\section{Methods}

We have studied the historical literature on this issue as well as British newspapers from the Victorian age. Moreover, we have carried out an analysis of photographs and iconography, supporting this study with interviews with museum curators where these post-mortem photos are exhibited.

\section{Results}

The results of this study show that there were three iconographical styles of post mortem photography.

\section{The first style}

Of the three different models proposed for a classification of post-mortem photography (Ruby, 1995), the first is certainly the most important when attempting to define a symbolic-allegorical reflection. This first style was defined "the last sleep". Perhaps the goal was that of postponing pictorial representations of the memento mori. This group includes all pictures in which the deceased is lying on a bed or on a couch. The body position and the makeup of the face give an expression of serenity. Portraying the person as if they were asleep was a way to conceal the reality of the moment. The memento mori photos and the paintings are an allegory of Death. They remind us that no one escapes that fate and they guide us towards the acceptance of it. The photo (Figure 1) is quite exemplificative of this first style. It shows a young girl lying on the bed, with her head resting on the pillow and a facial expression that appears quite alive. Numerous times, the actual state of death is emphasized by symbols such as crucifixes, flowers and holy books. The photo (Figure 2) is taken from the Paul Frecker London collection. It shows a woman's body stretched out on a couch, and on the right side of her head we see a Bible and a bouquet of flowers. Her hands are clasped in prayer. We imagine that the photographer wanted to underline the moment in which the "spirit leaves the body". Based on this viewpoint, it is interesting to analyse the visiting cards 
custom. These special cards show two photos: one of the dying and one of the dead. It involves taking a picture of a person in agony and then later in the immediate aftermath of death, simulating life, giving credibility to both photographs. An example is a visiting card taken in 1848 in New York. The first shot is a picture of a live baby lying on his left side. The baby turns to the camera and stares into the objective. In the second shot, he is dead and he is framed with his head resting on the pillow. This is the typical position of memento mori (Orlando, 2010: 60). These are reflections of the symbolic and allegorical aspect of this custom. However, to study this tradition means that we must also look at some interesting aspects about the funeral ceremonies during that time period, while examining the context that was obviously not provided by the photograph. Around the deceased lying in bed, in addition to the family and the priest (sometimes included in certain photos), the photographer and his assistants were also present, as well as their bulky equipment. Overall, this moment became a performance of death, rather than a commemoration.

\section{The second style}

In the second style is defined by the deceased's eyes staring into the lens. "Alive but Dead" is the title given to these images - the denial of death is much more evident. It is possible to observe the photographer's skill, who engaged in various artifices, such as hidden bars that supported the body in an upright position or wooden sticks to keep their eyes open. Sometimes pupils were drawn directly onto the photographs: a sort of ante litteram photoshop. In this regard, a photographer of the time stated

We recommended that eyes were left open, we placed him sitting next to a table and we had to wait to work seven or eight hours; in this way we could seize the moment when the twitching agony disappeared, we can play a semblance of life. This is the only way to get a satisfactory picture that does not remember the painful moment of the separation" (Bolloch, 2002).

In an attempt to understand the question of body manipulation and life simulation, we need to reconnect with other pictures in which the bodies appeared erected to stage real life. In 1873, the newspaper of photographic technique described these body treatments. It is possible to bend bodies 
until the joints remain flexible. This technique gives to the body a natural look. A good reference is that of the Italian brigands captured and killed during the repression campaign (Figure 3). They had their hands chained and they were tied to a tree. However, in the picture it appears as if they were alive. Clearly, in such cases the denial of death is carried out to mislead the public. These pictures testified the arrest of those who threatened public order. In order to reach this goal the photos were published in national and international newspapers. The post mortem photos of prisoners had the explicit function of propaganda. For this reason, these pictures were seen by the entire community. On the other hand, Victorian post mortem photos were addressed only to the family.

\section{The third style}

In the third style, the deceased person is hidden within the family, and usually it is quite difficult to recognize the deceased from the living. Furthermore, the typical funeral iconographs were not used. Only a meticulous observation can capture details to identify the deceased, such as: an expressionless look or the central position of the dead. The deceased was inserted perfectly as "alive among the living". (Figure 4)

\section{A fourth style?}

Based on our studies, we could also add an additional style, known as "the hidden mother". This style typically portrayed living children, using a special technique. The mother was sitting and she was covered by a draped sheet. The child was placed on the mother, and he was held by the hidden hands of the mother. Then, to cover the mother's silhouette, a card was placed up the printed photograph, creating a portrait of the child. The background was the decoration offered by the sheet. (Figure 5).

This technique was also useful when taking photographs of the lifeless bodies of dead children. In these photos, children appear alive, due to the fact that photographers often coloured their cheeks pink. However, by removing the card up the picture, the imagine was really impressive and it could trouble the observer who could not imagine an artifice like this. Behind the child, in fact, there was a figure completely covered with a sheet. Although this was not surprising during the Victorian age, since it was part of spiritualism, seen today this image is quite evocative. 
Melania Borgo, Marta Licata, Silvia Iorio, Post-mortem Photography: the Edge ...

HSS, vol. V, no. 2 (2016): 103-115

\section{Discussion}

Based on our study and analysis of literature and visual references, the first style does not offer clear signs that make us think of death. As a matter of fact, death was rather hidden, since it was considered something that could be shared only with the family. Those photos place the dead along the borderline between life and death. Later, in the twentieth century, images and photography came into daily family life, so that the representation of the living dead had no more reason to exist. Therefore, the custom ceased. Why continue to photo the deceased as if they were alive, if it is possible to take a portrait during life? It was no longer necessary to have such post-mortem photos, seeing that there were other ways to remember loved ones. As mentioned above, these pictures are not a macabre practice or an indicator of an obsession for death. By looking at this custom based on an understanding of Victorian culture, in fact, we can state that this custom has the opposite meaning. Those portraits are a demonstration of the full acceptance of death.

We know that post-mortem photos had great success. During this time, photographers, as well as the makeup artists, continually refined their techniques. The photographers improved the chiaroscuro of light and the makeup artists developed a flawless colour use. The results were "photorepresentational" masterpieces. Nadal, a famous New York photographer, took two photos to highlight the importance of the work of photographers as well as that of the makeup artists. He put two photos side by side (one before and one after the cosmetic care of the dead) of a woman who died of cancer in 1859. In the first photo, the deceased has a dehydrated face while in the second one, after makeup, she seems reinvigorated (Figure 6) (Orlando, 2010). Then, in 1865, in Philadelphia, Fredrik Gutekunst took a picture of a half-bust of a woman who had died many days before. $\mathrm{He}$ showed that it was possible to work with the body, even if it was in the advanced stage of putrefaction.

In post-mortem photos, it is sometimes difficult to recognize the deceased, specifically when the deceased is a child portrayed next to toys: in this case, the dead seemed to be in a "space of life". Unfortunately, we have to remember that these children's lives were dramatically short and the picture, taken at the time of death, represents the only image that parents could keep. In our paper, we would like to suggest that the representation 
of death through these portraits, in a certain period, was not just an expression of a shared custom, due to the fact that it could also have other meanings. With regard to this tradition, we could consider ancient forms of thanato metamorphosis aimed to preserve corpses (Orlando, 2010). Therefore, immortalizing death in a photograph was a way to give to the body a kind of visual mummification that would ensure an apparent integrity of the body by preserving this moment and preventing the later decomposition of the body. However, this tradition is similar but not identical to that of the Egyptians. The goal is different. We know that their artificial mummification was not used to preserve the image of the person, but rather to make the journey to the Hereafter possible. Post-mortem photos can be considered images of a funeral art much like the masks that ancient Romans made using a facial cast of the dead. Those masks were preserved in the homes of wealthy patricians, maintaining the memory of those who had died.

The first style focuses on people in their deathbed - this was a typical scene. When someone died at a hospital, in that time, loved ones waited to bring the body home. It is also interesting to look beyond the people on the bed and note the absolute naturalness of the composition and the lightness that suggest a sense of peace and tranquillity. Death is negated in a warm sleep of a body that seems to rest. A photograph taken by Blondel (1850) shows a father who seems to watch over his child while he is sleeping. This might seem like a normal everyday scene, were it not for the blinding light that illuminates the child's body and attracts our attention. In this case, the thin red line between sleep and death is made clear, on a figurative level, by the dualism of the cradle and the coffin. In the picture, on one side, we find a cradle (sign of birth and guardian of sleep) and, on the other side, just beyond the cradle, there is a coffin (sign of death and guardian of eternal sleep). Death and birth are twins, two sides of the same coin - to be born means to be projected towards death, while death also means rebirth. The gap between the cradle and the coffin is the same gap that exists between the joy of life and the fear of dying; however, in this picture, the cradle and the coffin could also be considered as two places related to rest. This thought is well represented in the second style of memento mori. The deceased seems to look around, his/her eyes are always expressionless, and they can be open or painted to appear open. Time is 
stopped in the photograph, the lifeless body of the deceased will change soon, so it is necessary to immortalize their image forever (since changing means also forgetting features), as well as their identity and dignity. Thanks to these photographs, they were able to preserve an image that the future will eventually destroy. These images are not representations of death. Their aim is to give life back to the body and, symbolically, enhance the revival of the spirit. The subjects appear alive thanks to artificial techniques developed by photographers. Victorian English, in fact, took photographs of their deceased simply to immortalize the image of their beloved.

Can we call these images "living corpses"? This definition can be used to indicate the subjects portrayed in post-mortem photography; however, in this way, we rediscover an unfounded prejudice according to which in Victorian society there was a certain inclining for grotesque and horror. Stemming from these preconceptions, or perhaps motivated by them, we were pushed to study the phenomenon of post-mortem photos, analysing its various stylistic forms and investigating the photographic techniques of that time. Moreover, by studying the iconography of these images, it has been possible to capture the allegory hidden there. By going beyond these negative connotations, we discover a little known aspect of Victorian society.

At the beginning of the twentieth century, the styles described above were gradually replaced by photos of the funeral itself. Pictures of the deceased were taken while the deceased lay inside the coffin. In time, the photographic iconography changed, along with the metaphorical language. The real protagonist of post-mortem photos is no longer the deceased, but rather the funeral. During the photo shoot, we find not only friends and relatives but also all the elements that make us think of death. Those symbols were never included in previous photos. Before these changes, death had to be "apparent", while now it is denied, emphasized and then photographed.

The first post-mortem photo was taken in 1840. The onset of the darkroom allowed photography and portraits to spread to a greater number of people, since costs were cheaper than painted portraits. However, it is also true that at that time the chance to be photographed was rare and memento mori could be the only possibility to have a portrait. Giving an appearance of life to the deceased and eliminating signs of disease was a 
way to remember beloveds as alive and respect the funeral ceremony. Human suffering, even if it is no longer present on the deceased face, is still found in the photographs. We can find some iconographic elements, such as flowers, an hourglass, dark suits, etc. Those photographs were likely taken to remember the dead, but also to remind us that we will all die one day. In the Victorian Age, references to the bereaved are less evident in the first pictures when compared to the last. In the first style, memento mori was kept secret and was revealed only to family members; in the second, on the other hand, the moment of the funeral was a way to remember not only the dead, but also the fact that one day we will die.

In time, people began taking portraits during their life, and post-mortem photography lost a great deal of its role in life and death. This marked the end of memento mori photography and the beginning of the funeral photography. The latter, in fact, was created to remember a person during this moment, along with the other pictures that had taken while they were alive.

Some years ago, when seeing his dead mother, a man expressed his feeling on this practice, perhaps connecting death photography with funeral photography:

When my mother died of lung cancer five years ago, I was shocked and embarrassed to see my niece photographing the coffin. I thought she was doing something that was indelicate and disrespectful, but I said nothing. The following week, my niece brought these pictures to my house. I thanked her, and I put the photos away without even opening the envelope. A few months later, I found the envelope, between two books, and I decided to open it. I had forgotten that my mother was so beautiful. All the months at hospital had been so full of suffering that my last memories of this dear woman had broken my heart. These photos were helpful and comforting. I'm so happy to have them (Orlando, 2010). 
Melania Borgo, Marta Licata, Silvia Iorio, Post-mortem Photography: the Edge ...

HSS, vol. V, no. 2 (2016): 103-115

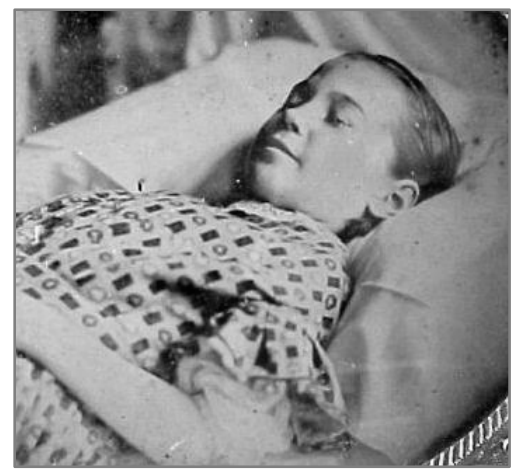

Fig. 1: An exemplification of the first style of post-mortem photography: a young girl lying on the bed

Fig. 2: An exemplification of the first style of post-mortem photography: a woman's body lies on a couch; on the right side of her head there are a Bible and a bouquet of flowers
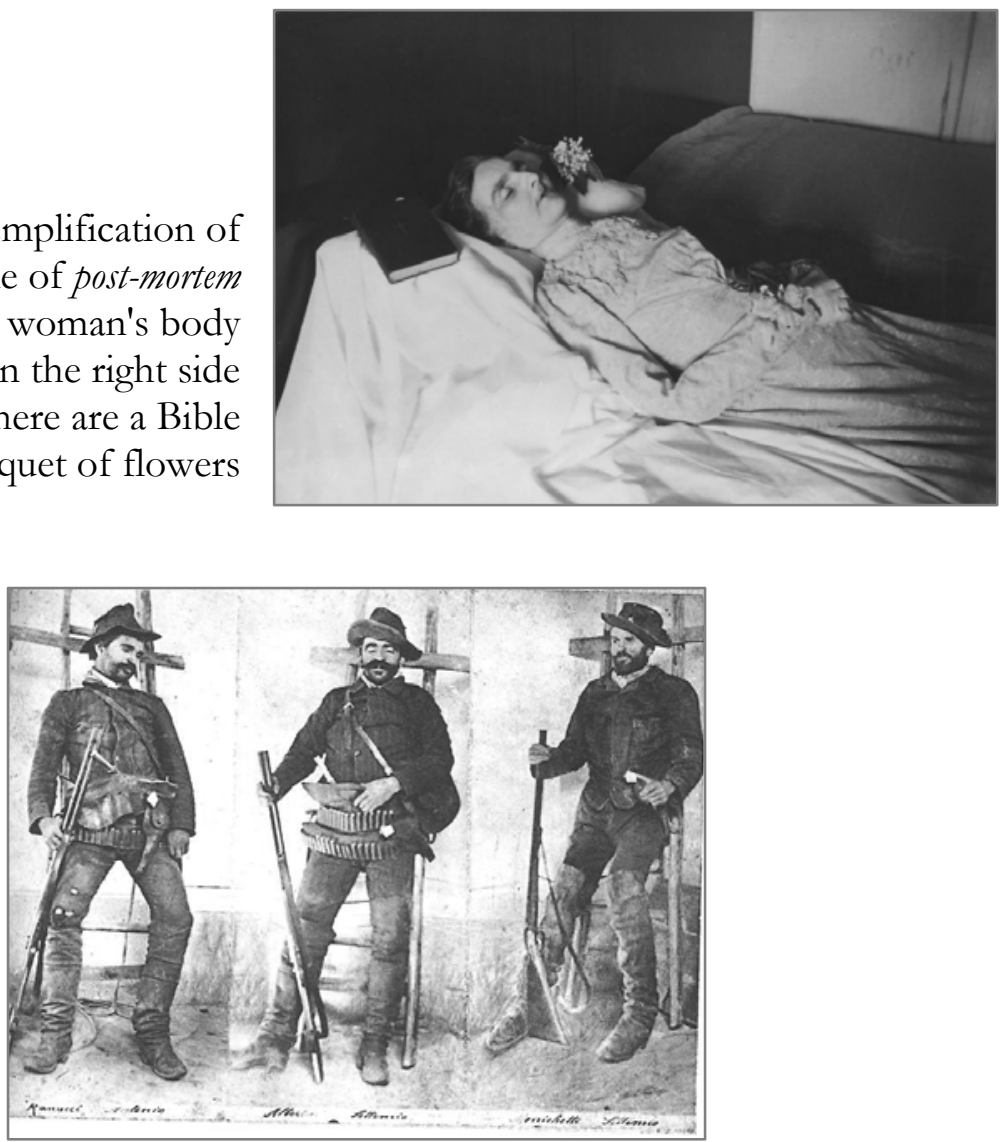

Fig. 3: An exemplification of the second style of post-mortem photography: Italian brigands captured and killed during the repression campaign 
Melania Borgo, Marta Licata, Silvia Iorio, Post-mortem Photography: the Edge ...

HSS, vol. V, no. 2 (2016): 103-115

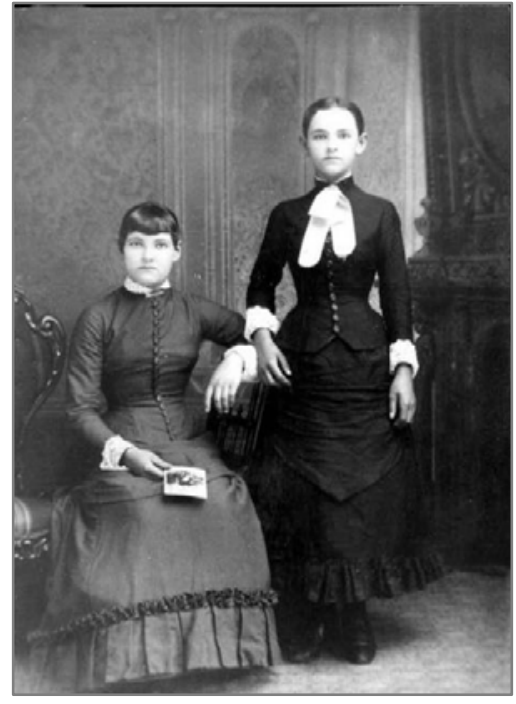

Fig. 4: An exemplification of the third style of post-mortem photography: who is the dead girl?

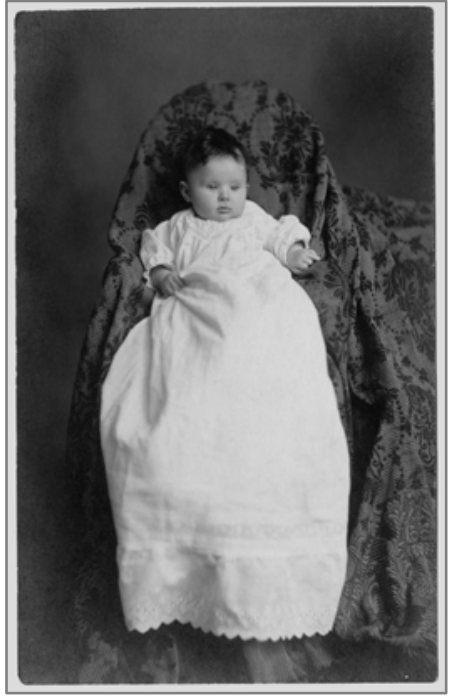

Fig. 5: An exemplification of the fourth style of post-mortem photography: a "bidden mother"

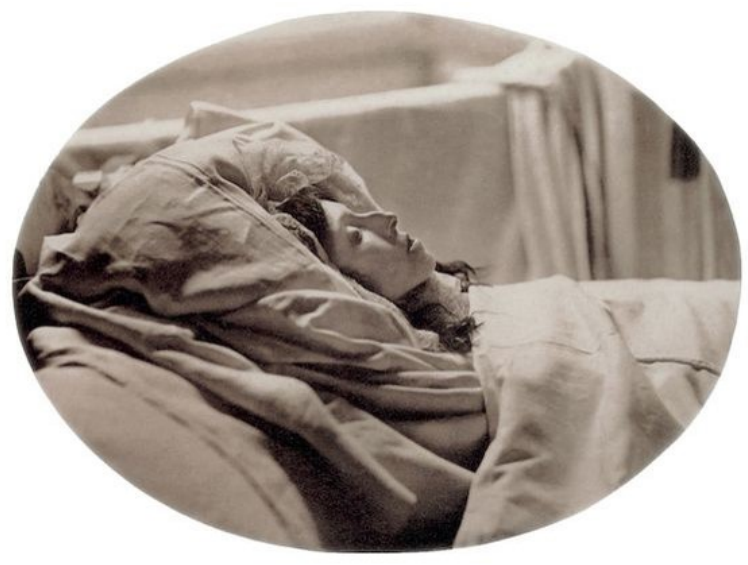

Fig. 6: A girl after the mortuary toilet: she seems reinvigorated 


\section{References}

Arbus, D. (1972). Diane Arbus. New York: Aperture.

Bauman, Z. (2003). Intervista sullidentità. Roma: Laterza.

Ariès, P. (1975). Essais sur l'bistoire de la mort en Occident. Milano: Rizzoli.

Blauner, R. (1966). "Death and Social Structure". Psychiatry, 29, p. 379.

Baudrillard, C. (1976). L'échange symbolique et la mort. Gallimard: Collection Bibliothèque des Sciences humaines.

Bolloch, J. (2002) Photographie après décès: pratique, usage et fonctions. Paris: Musèe d'Orsay.

Burns, S., Burns, E.A. (2002). Sleeping BeautyII: Grief, Bereavement and the Family in Memorial Photography American and European Tradition. New York: Burn Archive Press.

Castel, R., (2004). "Immagini e fantasmi”. La fotografia: usi e funzioni sociali di un'arte media. P. Bourdieu, Rimini: Guaraldi.

Croce, B. (1902) Estetica come scienza dell'espressione e linguistica generale. Bari: Laterza.

Dubois, P. (1990) L'acte photographique et autres essais. Bruxelles: Labor.

Eco, U. (2001) Sugli specchi ed altri saggi: il segno, la rappresentazione, l'illusione, l'immagine. Milano: Bompiani.

Freund, G. (1974). Photographie et sociéte. Paris: Le Seuil.

Licata, M. (2013). "Cadavere e fotografia: origine e sviluppo del memento mori, una usanza funeraria ottocentesca poco conosciuta". Rivista di Storia della Medicina. XXIII NS (XLI). 109-118.

Lesy, M. (1973). Wisconsin death trip, New York: Panethon.

Orlando, M. (2010) Ripartire dagli addii. Uno studio sulla fotografia post-morte. Meda: MJM.

Roh, F. (2007) Foto-Auge, Napoli: Liguori.

Ruby, J., (1995). Secure the shadow: death and photography in America. Massachusetts: MIT.

Rinhart, F., Rinhart, M. (1967). "Rediscovery: an America Way of death". Art in America.

Thomas, L.V. (1976) Anthropologie de la mort. Paris: Payot Bibliothèque scientifique.

Welling, W.B. (1978) Photography in America, the Formative Years. New York: Crowell. 


\section{Biographical notes}

Silvia Iorio is a Medical Anthropologist and $\mathrm{PhD}$ in Medicine and Human Sciences. Currently she is a Research Fellow at the Department of Molecular Medicine, Unit of History of Medicine, Sapienza University of Rome, working on issues of health inequalities. Her interests are History of Medicine, Bioethics, Medical Anthropology and Anthropology.

Melania Borgo obtained her doctorate in Medicine and Human Sciences from Insubria University (Varese, Italy). Her current research interests include clinical ethics, as well as cultural anthropology and medical history. She has been a speaker at several conferences and she is an author of scientific publications.

Marta Licata is Archaeologist and Anthropologist with expertise in Funeral Archaeology. She works in archaeological context, in particular in North West Lombardy necropolis area. Her accademic interests are History of Medicine, Physical Anthropology and Paleopathology. 